\title{
Modelling soil moisture under different land covers in a sub-humid environment of Western Ghats, India
}

\author{
B Venkatesh ${ }^{1, *}$, Lakshman Nandagiri ${ }^{2}$, B K Purandara ${ }^{1}$ and V B Reddy ${ }^{3}$ \\ ${ }^{1}$ National Institute of Hydrology, Hanuman Nagar, Belgaum 590 001, India. \\ ${ }^{2}$ Department of Applied Mechanics \&3 Hydraulics, National Institute of Technology, \\ Surathkal, Mangalore 575 025, India. \\ ${ }^{3}$ The Energy Research Institute, Alto, St. Cruz, Bambolin, Panaji 403 20\%, Goa, India. \\ *e-mail: bvenki30@yahoo.com
}

\begin{abstract}
The objective of this study is to apply and test a simple parametric water balance model for prediction of soil moisture regime in the presence of vegetation. The intention was to evaluate the differences in model parameterization and performance when applied to small watersheds under three different types of land covers (Acacia, degraded forest and natural forest). The watersheds selected for this purpose are located in the sub-humid climate within the Western Ghats, Karnataka, India. Model calibration and validation were performed using a dataset comprising depth-averaged soil moisture content measurements made at weekly time steps from October 2004 to December 2008. In addition to this, a sensitivity analysis was carried out with respect to the water-holding capacity of the soils with the aim of explaining the suitability and adaptation of exotic vegetation types under the prevailing climatic conditions. Results indicated reasonably good performance of the model in simulating the pattern and magnitude of weekly average soil moisture content in $150 \mathrm{~cm}$ deep soil layer under all three land covers. This study demonstrates that a simple, robust and parametrically parsimonious model is capable of simulating the temporal dynamics of soil moisture content under distinctly different land covers. Also, results of sensitivity analysis revealed that exotic plant species such as Acacia have adapted themselves effectively to the local climate.
\end{abstract}

\section{Introduction}

Soil moisture is widely recognized as a key variable in studies related to environment, meteorology, hydrology, agriculture and climate change. From a hydrological viewpoint, soil moisture content controls the partitioning of rainfall into runoff and infiltration and therefore has an important effect on the runoff response of a catchment (Aubert et al 2003). The role of soil moisture in a number of hydrological processes has been extensively studied over the last few decades at catchment scale and has received increasing attention from the hydrological scientific community. However, soil moisture is one of the most difficult variables to estimate because of its interaction with factors such as vegetation, soil and topography. Accurate estimation of spatial and temporal variations of soil moisture may therefore be useful in improving both the predictive capability of runoff models as well as the validation of hydrological process representations. Hence, datasets of observed in situ moisture measurements are crucial. Unfortunately, measured soil moisture time series are not widely available and therefore simulated soil moisture series are used to support physical reasoning and hypothesis (Wilson et al 2005).

Keywords. Western Ghats; soil moisture modelling; Acacia; atmosphere-soil-vegetation interaction. 
In recent years, a number of hydrological modelling studies have been undertaken to explore the relationship between soil moisture and other influencing factors. Water balance models have been extensively used to simulate soil moisture. Milly (1994) demonstrated the applicability of a simple water balance model across large areas of the United States. Georgakakos and Baumer (1996) developed a simple process-based model to simulate the soil moisture series at a monthly scale. Scanlon and Albertson (2003) developed a simple water balance model with a representation of climate-soil-vegetation interactions and the dynamic adaptive behaviour of vegetation in controlling the space-time patterns of water balance variability. Recently, Brocca et al (2008) used a simple conceptual model to simulate the soil moisture balance using different methods of infiltration and drainage estimation. Other modelling studies (Canadell et al 1996; Zobel 1992) have identified soil moisture storage capacity as a controlling factor for suitability, sustainability and survival of vegetation. Attempts have also been made to evaluate the influence of land cover on soil moisture predictions using water balance models (Federer 1979, 2002). However, few such modelling studies have been undertaken in the Western Ghats region of India, where all the major rivers of peninsular India originate. Over the last decade, significant changes have taken place in the land-use/cover of the Western Ghats region, through deforestation and simultaneous afforestation of degraded lands and grass lands, by planting exotic species such as Acacia (Jha et al 2000). Large-scale plantation of exotic species in parts of Western Ghats may have a detrimental impact on the hydrology of the region (Vandana and Bandyopadhyay 1983), specifically on the soil moisture regime and subsurface water (Calder et al 1992).

Hence, this study was taken up with the objective of applying a conceptual model developed by Georgakakos and Baumer (1996) to simulate the temporal variation in profile soil moisture in three small watersheds possessing distinctly different land covers (natural forest, degraded forest and Acacia plantation). The watersheds are located in the Western Ghats mountain ranges of Uttara Kannada District, Karnataka, India. The aim was to characterize the differences in model parameters for the different land covers when the model was calibrated with observed soil moisture measurements made at weekly time steps at four sampling points under each of the selected land covers from October 2004 to December 2008. Also, sensitivity analysis with respect to the effect of soil moisture storage capacity on water balance components for each watershed was performed. Finally, the adaptation of exotic tree species such as
Acacia to local climatic conditions, was investigated by estimating the rate of annual evapotranspiration, which is used as a proxy for plant growth.

\section{Study region}

The Western Ghats, locally called as 'Sahayadri Mountains', is a range of mountains in peninsular India running approximately parallel to the west coast and home to the largest tracts of moist tropical forests in the country. Uttara Kannada district in Karnataka has the biggest share of moist tropical forests. The district straddles the ghats, which are at their lowest elevation here $(<600 \mathrm{~m})$ and are about $20-25 \mathrm{~km}$ inland. East of the crest line of the ghats are rolling hills with forested slopes and shallow valleys with cultivation. This region, locally known as Malnad, covers most of the Siddapur, Sirsi and Yellapur taluks. The selected watersheds are located in Siddapur taluk.

The geology of the area consists of Dharwar (chlorite) schists, granitic gneisses and charnockites from the Archanea complex (Bourgeon 1989). Broadly, the soils of this region have been categorized as red sandy or sandy-clay loams (Kamath 1985), or more specifically by Bourgeon (1989) as mainly ferrallitics (French soil taxonomy) or alfisols and inceptisols (USDA soil taxonomy) (USDA, NRCS 2008).

\subsection{Experimental sites}

The watersheds selected for the study (figure 1) are situated on the leeward side of the Sahayadri Mountains. This study considers three watersheds, one each under natural forest, degraded forest and Acacia plantation. The areas of these selected watersheds are 7, 9 and 6 ha, respectively. These watersheds lie between $74^{\circ} 47^{\prime} 20^{\prime \prime}$ to $74^{\circ} 52^{\prime} 30^{\prime \prime} \mathrm{E}$ and $14^{\circ} 22^{\prime} 20^{\prime \prime}$ to $14^{\circ} 22^{\prime} 30^{\prime \prime} \mathrm{N}$.

A meteorological observatory was established close to the Acacia watershed in the study area. The observatory is equipped with a recording and a non-recording rain gauge to measure rainfall. Air temperatures (maximum and minimum) and wet and dry bulb temperatures were also measured. The measurements were initiated in October 2004 and continued up to December 2008. Meteorological observations were assumed to represent all three watersheds. Average monthly water balance of the region was computed using the Thornthwaite-Mather approach and yielded a climatic class of 'humid climate with rainfall deficit during summer and winter' (Thornthwaite and Mather 1957). 


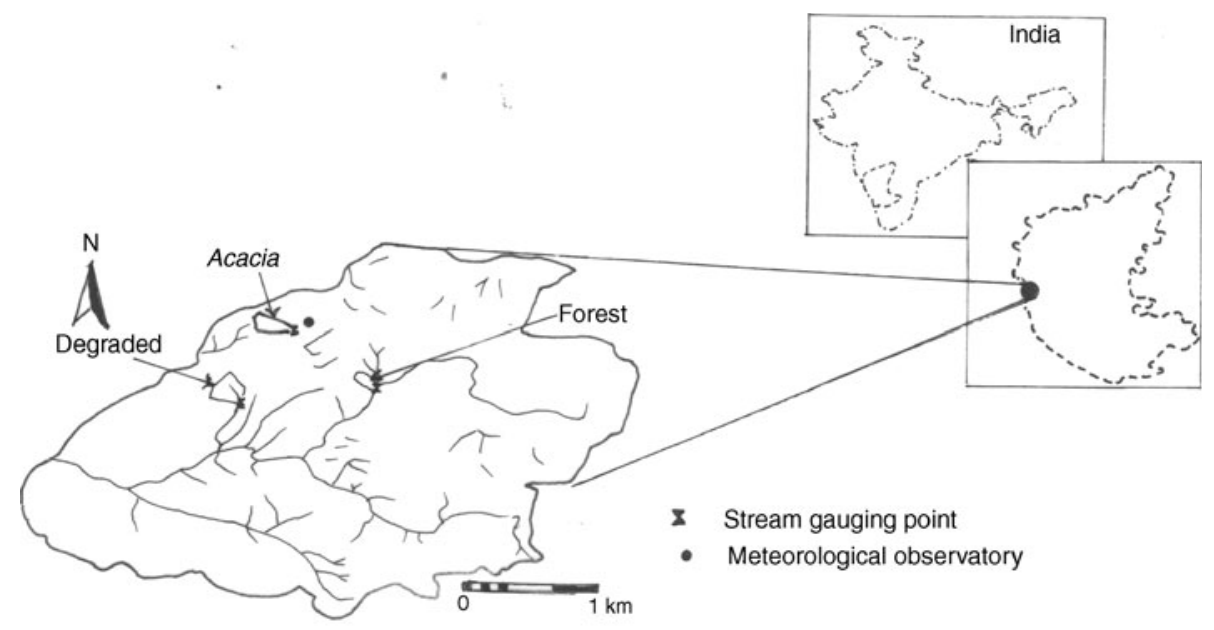

Figure 1. Index map of study area showing the selected watersheds.

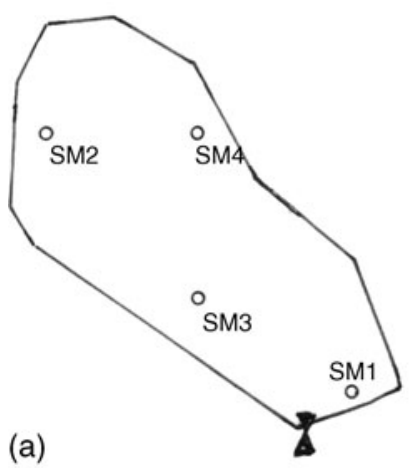

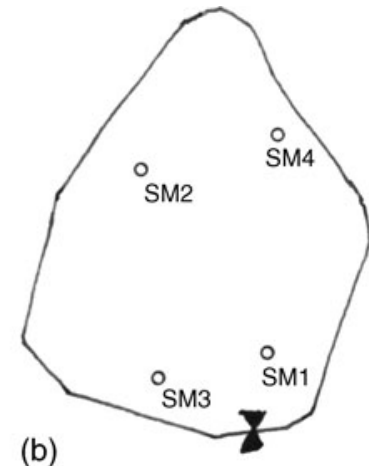

(b)

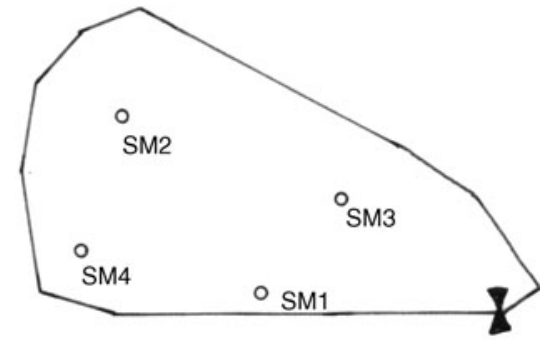

(c)

- Soil moisture measurement location

Flow measurement location

Figure 2. Spatial distribution of soil moisture measuring probes in (a) natural forest, (b) degraded forest, and (c) Acacia plantation watersheds.

Analysis of at-site climatic variables monitored between the years 2004 and 2008, revealed that mean monthly temperatures range between $20^{\circ}$ and $27^{\circ} \mathrm{C}$. The average annual rainfall is 2800 $\mathrm{mm}$ with significant intra-annual variability. About $70-80 \%$ of the rainfall occurs between June and September (south-west monsoon), while the other $20-30 \%$ is spread over the remaining 8 months of the year. The number of rainy days during June to September is about $100-110$. The net result is an effective dry season of almost 8 months.

\subsection{Soil moisture measurements}

Four sampling points were established for measuring the soil moisture content in each of the selected watersheds. These points are spread spatially across the watersheds (figure 2) so as to cover both topographic highs and lows. Soil matric potential measurements were made using resistance-type soil moisture probes developed by Water Mark ${ }^{\circledR}$. At each sampling point, probes were installed at three depths - 50, 100 and $150 \mathrm{~cm}$ so as to monitor soil moisture variations in the zone of maximum plant root activity. A roving instrument (handheld read-out unit) was used to record matric potential $(\mathrm{KPa})$ and expressed as soil matric head $(\mathrm{cm})$. Measurements were made at weekly time steps starting from October 2004 till the end of December 2008. Undisturbed soil samples were obtained from all three depths in each watershed and soil moisture retention curves were determined experimentally in the laboratory using pressure plate apparatus. The developed retention curves were used to convert the observed soil matric head values to equivalent values of volumetric soil moisture content $\left(\mathrm{cm}^{3} / \mathrm{cm}^{3}\right)$. 
Table 1. Soil particle size distribution and bulk density in selected land cover type.

\begin{tabular}{llcccc}
\hline Depth $(\mathrm{cm})$ & \multicolumn{1}{c}{ Land cover } & $\begin{array}{c}\text { Sand }(\%) \\
2-0.05 \mathrm{~mm}\end{array}$ & $\begin{array}{c}\text { Silt }(\%) \\
<0.05-0.002 \mathrm{~mm}\end{array}$ & $\begin{array}{c}\text { Clay (\%) } \\
<0.002 \mathrm{~mm}\end{array}$ & $\begin{array}{c}\text { Bulk density } \\
\left(\mathrm{g} / \mathrm{cm}^{3}\right)\end{array}$ \\
\hline \multirow{2}{*}{50} & Natural forest & 27.7 & 61.9 & 10.4 & 1.45 \\
& Degraded forest & 1.60 & 87.2 & 11.2 & 1.35 \\
\multirow{5}{*}{100} & Acacia & 27.9 & 62.1 & 10.0 & 1.4 \\
& Natural forest & 29.3 & 59.5 & 11.2 & 1.45 \\
\multirow{5}{*}{150} & Degraded forest & 25.9 & 63.7 & 10.4 & 1.2 \\
& Acacia & 41.2 & 49.2 & 9.6 & 1.5 \\
& Natural forest & 23.4 & 66.6 & 10.0 & 1.42 \\
& Degraded forest & 13.6 & 75.6 & 10.8 & 1.44 \\
& Acacia & 19.9 & 70.5 & 9.6 & 1.38 \\
\hline
\end{tabular}

\subsection{Soil physical characteristics}

In order to derive the requisite information on soil particle size distribution, soil samples were collected while installing the soil moisture probes at 50,100 and $150 \mathrm{~cm}$ depths. The samples were analysed in the laboratory for their texture by using the sieve method to quantify the coarse grains and by using the hydrometer method to determine the fractions of finer particles. Most of these samples are classified as clay loam as per USDA classification. The depth-wise variation of the soil texture in the watersheds is presented in table 1.

\section{Methodology}

\subsection{Model description}

The model proposed by Georgakakos and Baumer (1996) estimates soil moisture based on the water balance of an upper soil layer of thickness ' $D$ ' for a unit area. This zone is considered as a lumped system that receives input of infiltration from precipitation/irrigation and yields output of evapotranspiration and drainage. Spatial (vertical and lateral) variations in properties and processes are ignored and soil moisture content for the layer as a whole is modelled. Accordingly, application of water balance equation to the soil layer under these assumptions for time period ' $t$ ' yields;

$$
\begin{aligned}
W(t)= & W(t-1)+\operatorname{INF}(t)-\operatorname{EVP}(t) \\
& -\operatorname{PER}(t) W(t)<W_{\max },
\end{aligned}
$$

where $\operatorname{INF}(t)$ is the amount of rainfall infiltrating into soil, $\operatorname{EVP}(t)$ is the evapotranspiration rate, $\operatorname{PER}(t)$ is the drainage rate due to the interflow and/or the deep percolation (figure 3 ) and $W_{\max }$ is the maximum water capacity of the soil layer. The amount of water $W(t)$ in the soil layer investigated is given by $W(t)=\left[\theta_{\mathrm{t}}-\theta_{\mathrm{r}}\right] D$, where $\theta_{\mathrm{t}}$ is the volumetric water content at saturation and $\theta_{\mathrm{r}}$ is the residual volumetric water content. At natural saturation, $\theta_{\mathrm{t}}=\theta_{\mathrm{s}}$ and $W(t)=W_{\max }$.

Infiltration $[\operatorname{INF}(t)]$ is estimated using the following empirical equation,

$$
\operatorname{INF}(t)=P(t)\left(1-\frac{W(t)}{W_{\max }}\right)^{m},
$$

where $P(t)$ is the precipitation in millimetres and $m$ is a parameter linked to the nonlinearity of the infiltration process. The parameter $m$ is represented by values greater than unity, with larger values representing a highly nonlinear threshold behaviour; surface runoff is produced only when the soil water element is full (i.e., $W(t)=W_{\max }$ ).

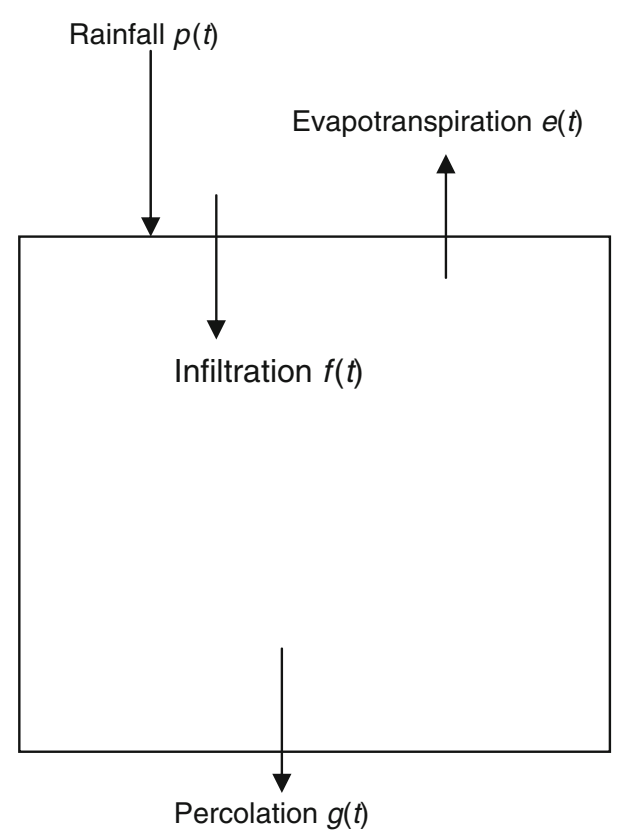

Figure 3. The root zone as a lumped hydrological system. 
The relationship adopted for the drainage component is based on the nonlinear relationship (Georgakakos and Baumer 1996) with $W(t)$, i.e.,

$$
\operatorname{PER}(t)=K_{\mathrm{s}}\left(\frac{W(t)}{W_{\max }}\right)^{3+\frac{2}{\lambda}}
$$

where $\lambda$ is the pore size distribution index linked to the structure of the soil layer (Maidment 1993) and $K_{\mathrm{s}}$ is the field-saturated hydraulic conductivity.

The magnitude of the fluxes on the right-hand side of equation (1), namely $\operatorname{EVP}(t)$ and $\operatorname{PER}(t)$ are all controlled by the soil moisture storage $W(t)$. To estimate these fluxes in terms of $W(t)$, the soil moisture capacity $W_{\max }$ is the limiting factor (Federer et al 2003; Struthers et al 2003). The parameter $W_{\max }$ represents the soil moisture storage capacity per unit area. In this study, the analysis of soil is restricted to $150 \mathrm{~cm}$ since the soil moisture time series data is available up to this depth. In any case, the zone of maximum root activity is not expected to exceed this depth.

Evapotranspiration, which mainly controls the soil moisture temporal pattern in the periods without rainfall, is represented by a linear relationship depending on the potential evapotranspiration $E_{\mathrm{p}}(t)$ and the soil saturation, i.e.,

$$
\operatorname{EVP}(t)=E_{\mathrm{p}}(t) \frac{W(t)}{W_{\max }}, \quad e(t) \leq E_{\mathrm{p}}(t)
$$

A variety of methods are available for computing $E_{\mathrm{p}}$ from ground-based climate measurements. Among these, the Food and Agriculture Organisation (FAO) Penman-Monteith method (Allen et al 1998) is considered to yield most accurate results in a wide range of climates (e.g., Nandagiri and Kovoor 2006). However, this method is data intensive and therefore attempts have been made to identify alternative methods which are less data intensive. In one of such study carried out considering different climates of India (Nandagiri and Kovoor 2006), the Turc method (Maidment 1993) has been recommended as the best alternative in sub-humid climates. Therefore, since the climate measurements in this study did not support the use of the Penman-Monteith method, the simpler Turc method was adopted to compute potential evapotranspiration $\left(E_{\mathrm{p}}\right)$.

The Turc method uses the following equations to estimate $E_{\mathrm{p}}$.

$$
E_{\mathrm{p}}(t)=a_{\mathrm{t}} 0.013 \frac{T_{\text {mean }}}{T_{\text {mean }}+15} \frac{23.8856 R_{\mathrm{s}}+50}{\lambda},
$$

where $E_{\mathrm{p}}(t)$ is the potential evapotranspiration $\left(\mathrm{mm}\right.$ day $\left.^{-1}\right), T_{\text {mean }}$ is the mean daily air temperature $\left({ }^{\circ} \mathrm{C}\right), R_{\mathrm{s}}$ is the solar radiation $\left(\mathrm{mm}\right.$ day $\left.^{-1}\right)$.
The coefficient ' $a_{\mathrm{t}}$ ' is a humidity-based value, if the mean daily relative humidity $\left(\mathrm{RH}_{\text {mean }}\right)$ is greater than or equal to $50 \%$, then $a_{\mathrm{t}}=1.0$; if $\mathrm{RH}_{\text {mean }}$ is less than $50 \%$, then $a_{\mathrm{t}}$ has the value of:

$$
a_{\mathrm{t}}=1+\frac{50-\mathrm{RH}_{\text {mean }}}{70} .
$$

The value of solar radiation $\left(R_{\mathrm{s}}\right)$ was estimated by using the Hargreaves model as described by Allen et al (1998):

$$
R_{\mathrm{s}}=K_{\mathrm{RS}} \sqrt{\left(T_{\mathrm{Max}}-T_{\mathrm{Min}}\right) R_{\mathrm{a}}},
$$

where $K_{\mathrm{RS}}$ is an adjustment coefficient, $T_{\max }$ and $T_{\min }$ are the daily maximum and minimum air temperatures $\left({ }^{\circ} \mathrm{C}\right)$, and $R_{\mathrm{a}}$ is the extraterrestrial radiation $\left(\mathrm{MJ} \mathrm{m}^{-2}\right.$ day $^{-1}$ ). A value of 0.16 was used for $K_{\mathrm{RS}}$ as suggested by Allen et al (1998) for inland locations. $R_{\mathrm{a}}$ is determined from latitude and the time of the year, i.e., 1 January as Day 1 and 31 December as Day 365 or 366 which form the inputs for the equations given in Allen et al (1998). $\mathrm{RH}_{\text {mean }}$ and $T_{\text {mean }}$ are computed using the observed maximum and minimum relative humidity and temperature at the experimental site.

\subsection{Model application and validation}

The soil moisture simulation model was applied using a daily time step (i.e., $t=$ one day). Equations (1-4) indicate that the model requires data of rainfall $(p)$ and potential evapotranspiration $\left(E_{\mathrm{p}}\right)$ for simulating the soil moisture content. As stated earlier, observed depth-wise soil moisture content data at weekly time step was available from October 2004 to December 2008. Data from October 2004 to December 2007 was used for calibrating the model while the remaining data, i.e., from January 2008 to December 2008 was used for validating the model. At each sampling point, depth-wise soil moisture measurements were integrated over the $1.5 \mathrm{~m}$ depth to arrive at a single value of observed soil moisture content using the following equation:

$$
M_{i}=\frac{1}{N_{1} N_{\mathrm{t}}} \sum_{j=1}^{N_{1}} \sum_{k=1}^{N_{\mathrm{t}}} M_{i, j, k},
$$

where soil moisture content of site $i$, layer $j$ and sampling occasion $k$ is expressed as $M_{i, j, k}$ and let $N_{\mathrm{p}}$ be the number of sites, $N_{\mathrm{l}}$ the number of sampling layers or depths and $N_{\mathrm{t}}$ the number of sampling occasions. These values were averaged across the four sampling points to calculate a value of observed soil moisture content $\left(O_{i} \mathrm{~mm}\right)$ for each 
week in each watershed and compared with profile soil moisture content values simulated by the model $\left(P_{i} \mathrm{~mm}\right)$. Weekly totals of measured rainfall depths and computed $E_{\mathrm{p}}$ values for these periods were used as inputs.

The model has four parameters $-m, W_{\max }$, $K_{\mathrm{s}}$ and $\lambda$, whose optimal values are determined through model calibration. Criterion for optimality was minimization of root mean square error between weekly observed and simulated soil moisture values. Optimization of model parameters was performed with Newton search algorithm using the SOLVER add-in in MS-Excel ${ }^{\circledR}$ with a convergence limit of $10^{-4}$. Model simulations require an initial value of profile soil moisture $\left(W_{\text {initial }}\right)$ and estimated soil moisture can be considerably influenced by this value. Therefore, in this study, $W_{\text {initial }}$ was also treated as a parameter and the optimal value was determined through calibration. Optimization was initiated with the following parameter values, $m=0.1, W_{\max }=500 \mathrm{~mm}, K_{\mathrm{s}}=10 \mathrm{~mm} / \mathrm{h}$ and $\lambda=0.1$ and $W_{\text {initial }}$ was set to $120 \mathrm{~mm}$ which corresponds to the lowest observed profile soil moisture value.

The following model performance evaluation measures were used for comparing observed and predicted soil moisture values both in calibration and validation phases - coefficient of determination $\left(R^{2}\right)$, mean absolute error (MAE) and root mean square error (RMSE). In addition, the index of agreement $(d)$ defined as follows was also used.

$$
d=1.0-\left(\frac{\sum_{i=1}^{n}\left(O_{i}-P_{i}\right)^{2}}{\sum_{i=1}^{n}\left(\left|P_{i}-\bar{O}\right|+\left|O_{i}-\bar{O}\right|\right)^{2}}\right),
$$

where $O_{i}$ and $P_{i}$ are observed and predicted soil moisture values in the $i$ th week, respectively. $\bar{O}$ is the average value of observed soil moisture values and ' $n$ ' is the number of values used for computing the $d$ index. The $d$ index penalizes the model for consistently overestimating or underestimating even though the correlations may be high (Legates and McCabe 1999). This index ranges from 0.0 to 1.0. Higher values indicate better agreement between simulated and measured values.
Further, the soil moisture storage capacity $\left(W_{\max }\right)$ was considered for sensitivity analysis, since it is a critical parameter (Atkinson et al 2002; Lacambra et al 2010) which controls the supply of soil moisture for evapotranspiration and drainage. Model simulations were performed covering the full range of possible values for the bucket capacity $W_{\max }$ and annual totals of water balance components of evapotranspiration, drainage and the soil moisture storage were recorded for each simulation run. Using the basic hypothesis that tree species develop strategies to maximize their productivity within the available limited resources and withstand periodic shortages of these resources that arise due to the natural variability of climate (Zobel 1992), these results were used to investigate whether Acacia had adapted itself to the hydro-climatic conditions in the Western Ghats.

\section{Results and discussion}

An overview of the model performance during calibration and validation phases can be seen in the statistics presented in table 2 . In terms of $R^{2}$, the model performance appeared to be best for natural forest cover and relatively poorer for degraded forest. However, in all the considered cases, $R^{2}$ was reasonably high indicating reasonably good model performance in both calibration and validation. MAE values in calibration range from 57.15 to $64.72 \mathrm{~mm}$, with slightly higher values being obtained during validation. In terms of RMSE, the model appeared to perform best for degraded forest during calibration, but the highest value was obtained for degraded forest cover during validation. The value of $d$ index varied between 0.912 for degraded forest and 0.948 for natural forest during calibration. Except for the case of degraded forest, the $d$ index values were higher during validation indicating reasonably good model performance in simulating profile soil moisture content. These results were further supported by the lower values of relative root mean square error (RRMSE).

Table 2. Model performance statistics in calibration and validation phases.

\begin{tabular}{llrcrrc}
\hline Land use & & $R^{2}$ & MAE $(\mathrm{mm})$ & RMSE $(\mathrm{mm})$ & $d$ index & RRMSE $(\%)$ \\
\hline Natural forest & Calibration & 0.945 & 44.5 & 56.90 & 0.966 & 0.137 \\
& Validation & 0.889 & 126.82 & 147.69 & 0.966 & 0.311 \\
Degraded forest & Calibration & 0.85 & 72.49 & 94.66 & 0.90 & 0.239 \\
& Validation & 0.77 & 119.00 & 133.08 & 0.927 & 0.420 \\
Acacia & Calibration & 0.918 & 54.28 & 62.49 & 0.957 & 0.178 \\
& Validation & 0.954 & 100.96 & 117.21 & 0.930 & 0.366 \\
\hline
\end{tabular}



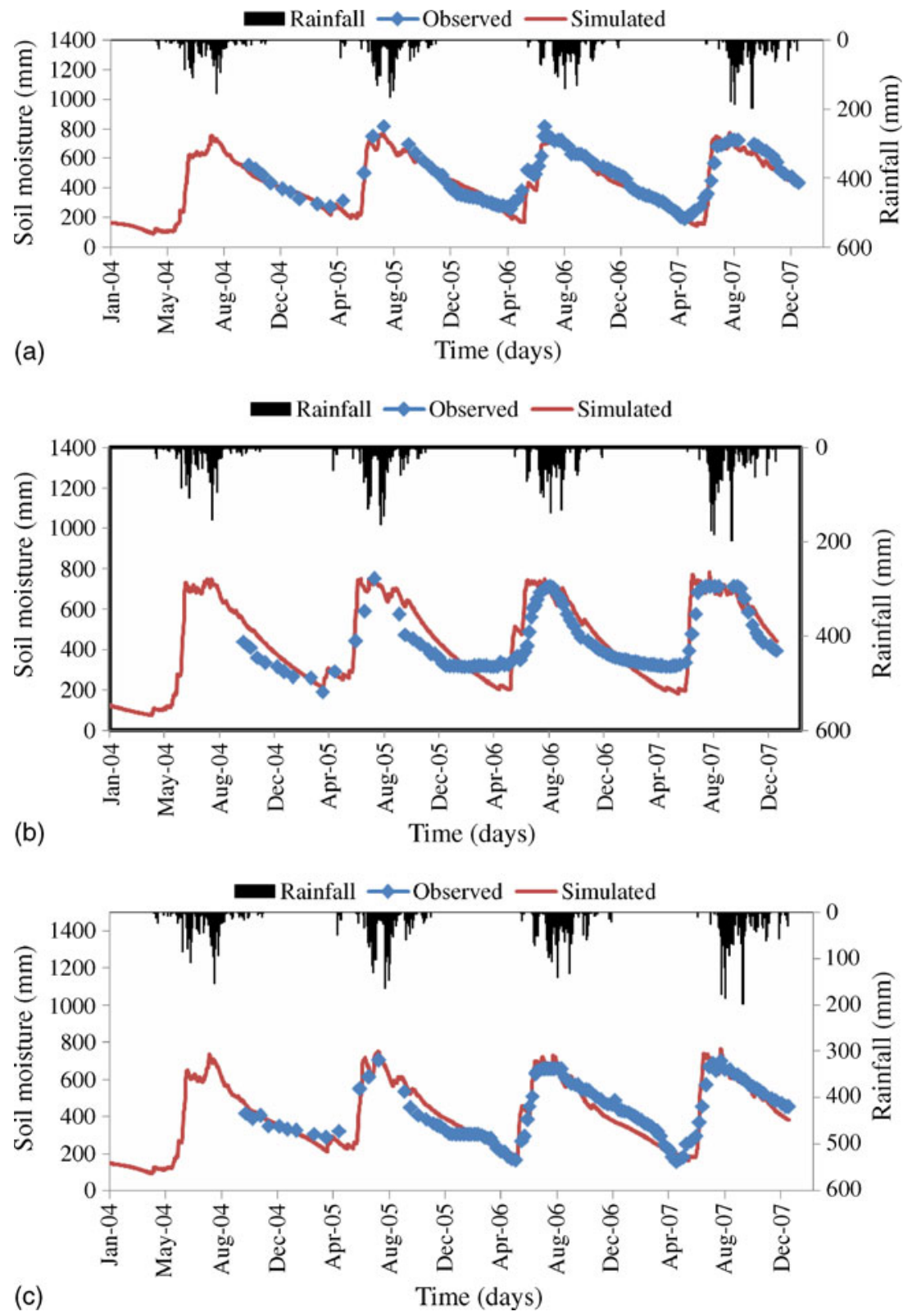

Figure 4. Observed and simulated soil moisture under different land uses during calibration period, (a) natural forest, (b) degraded forest, and (c) Acacia.

The lower value of RRMSE was observed during calibration compared to the validation period.

Time series plots comparing simulated and observed values of profile soil moisture at weekly time steps for the calibration period (October 2004 to December 2007) are presented in figure 4. From these plots, it can be seen that there is a good agreement between the time evolution of observed and simulated values of soil moisture. Also, it is found that the phase and the amplitude of modelled and observed soil moisture values are in reasonably good agreement except during the dry season from November 2005 to April 2006 (figure 4). On some occasions, peak soil moisture values are either overestimated (Acacia) or underestimated (degraded forest) by the model. The model appears to be very sensitive to the rainfall amount with overestimation of soil moisture being associated with large rainfall events. Model performance seems to be significantly better during periods of moisture recession for all the three land covers.

The plots comparing observed and simulated soil moisture values during model validation are shown in figure 5. From these plots, it can be seen that the model overestimates lower soil moisture values and underestimates higher soil moisture values for all the land covers. However, overall model 

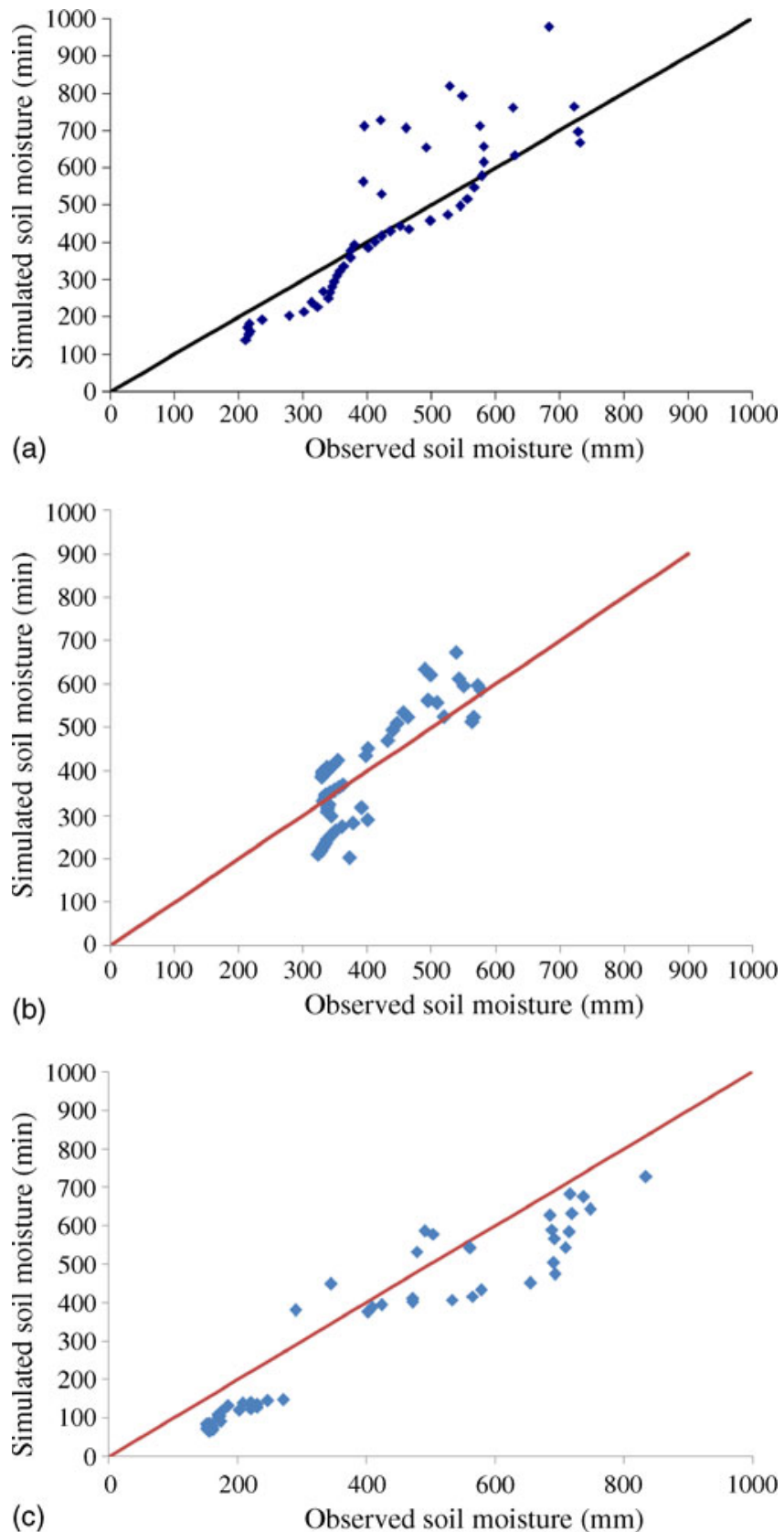

Figure 5. Comparison of observed and simulated soil moisture under different land uses during validation, (a) natural forest, (b) degraded forest, and (c) Acacia.

performance during validation appears to be reasonable since the data points are clustered around the line of equality. As can be seen in figure 5(ac), in most cases, the relative error is less than
20 to $25 \%$ with the higher value of about $56 \%$ observed under the natural forest watershed. It has to be pointed out that the higher values of the relative errors were concentrated in the higher range. As reported by Brocca et al (2008) and Blyth (2002), improper representation can induce a higher evapotranspiration thereby reducing the contribution towards the soil moisture augmentation and also drainage. This could be true in the present case, where the evapotranspiration component in the model is approximated using the Turc method in place of the FAO-recommended Penman-Monteith.

The optimized parameters of the model which yielded the simulations in calibration and validation are listed in table 3 . Although these are purely fitting parameters which ensure minimization of error between observed and simulated values of soil moisture, the relative differences in their values between the land covers considered for study may provide an interpretation on model parameterization. Firstly, most of the parameters shown in table 3 differ from one land cover to the other, thereby indicating the ability of the model to capture differences in hydrological behaviour as influenced by land cover. Also, the values of certain parameters appear to be physically reasonable. The range of values for variable $m$ can vary between 0 and 16 (Brocca et al 2008). Similarly the values for parameter $\lambda$ can vary between 0 and 1 . The value of parameter $m$ for the natural forest is actually higher than that for degraded forest $(0.75$ vs. 0.15$)$. The other parameter which influences the drainage processes is $K_{\mathrm{s}}$. The optimized $K_{\mathrm{s}}$ value for natural forest is $32 \mathrm{~mm} / \mathrm{h}$ in comparison to $15 \mathrm{~mm} / \mathrm{h}$ for the degraded forest cover. The higher value for parameter $m$ in combination with the lower value of $K_{\mathrm{s}}$ would produce a higher flow. A similar combination of parameters was used in TOPMODEL (Beven et al 1995), where the combination not only produces higher flow, but with a well defined shallow recession. In the present analysis, the values of $m$ and $K_{\mathrm{s}}$ obtained for natural forest are comparatively higher. This combination of values may induce a lower flow with a well-defined recession, which is quite evident in the simulations of soil moisture values (figure 4). The production of lower runoff from forested watershed may result in augmentation of soil moisture over a period of time.

Table 3. Optimized parameters of the model.

\begin{tabular}{lccccc}
\hline Land use & $m$ & $\begin{array}{c}K_{\mathrm{s}} \\
\left(\mathrm{mm} \mathrm{h}^{-1}\right)\end{array}$ & $\begin{array}{c}W_{\max } \\
(\mathrm{mm})\end{array}$ & $\begin{array}{c}W_{\text {initial }} \\
(\mathrm{mm})\end{array}$ & $\lambda$ \\
\hline Natural forest & 0.75 & 32 & 840 & 170 & 0.25 \\
Degraded forest & 0.15 & 15 & 730 & 125 & 0.36 \\
Acacia & 0.55 & 22 & 787.5 & 150 & 0.9 \\
\hline
\end{tabular}


Thus, the simulated lower soil moisture values are always higher than that of the observed lower soil moisture values. The optimized values for Acacia watershed lie between the values obtained for these two watersheds. The impact of higher values of $m$ and lower $K_{\mathrm{s}}$ values can be seen in figure 4(c), for Acacia, where the recession is quite smooth and follow the trend of observed soil moisture values. However, in case of degraded forest, both $m$ and $K_{\mathrm{s}}$ values are comparatively low. This combination can result in a longer recession with higher flows, which is seen in figure 4(b).

The optimized saturated hydraulic conductivity values obtained through the model lies within the range of values as reported by Bonell et al (2010). The authors have reported values varying between 25.76 and $39.9 \mathrm{~mm} \mathrm{~h}^{-1}$ under natural forest, 12.70 and $34.23 \mathrm{~mm} \mathrm{~h}^{-1}$ for degraded forest and 15.6 and $40.9 \mathrm{~mm} \mathrm{~h}^{-1}$ for Acacia through their experimental work carried out in Uttara Kannada district. Results obtained through the modelling clearly indicate that the Acacia plants help in ameliorating the soil properties and the possibility of influencing the water balance components. Similarly, the impact of $W_{\text {initial }}$ (the soil moisture at the beginning of the calibration period) can be seen through the better simulation of soil moisture values; since, in this study, the initial soil moisture value was set close to the lowest observed value. The higher initial soil moisture value has resulted in changes in the water balance component under the selected land covers.

The overall water budget components obtained for optimal model parameters set is presented in table 4 . Table 4 shows a steady increase in the water budget component as the amount of rainfall increases during the study period. The amount of actual evaporation simulated by the model is well within the maximum limit for natural forest as reported in the literature on humid tropical region (Bruijnzeel 1990, 2004; Scott et al 2004) and for Acacia plants (Kallarackal and Somen 2008). In Acacia plants, the amount of evaporation does not show high variation in spite of the large variation in observed rainfall. However, actual evaporation under natural forest appears to increase proportionately with the amount of rainfall.

As expected, the degraded forest cover does not contribute much to drainage, as most of the rainfall is converted to runoff due to degradation of soil hydraulic properties. Bonell et al (2010) have reported an order of magnitude difference in the saturated hydraulic conductivity under the degraded cover in the study region. However, there is a clear increase in the drainage component under natural forest and Acacia with increase in rainfall. At the same time, the drainage component of the water balance seems to increase with the rainfall amount under natural forest and Acacia plantation. This is further supported by the findings of Bonell et al (2010) who report that sub-surface stormflow and vertical percolation are dominant flow paths. These flow paths enhance the contribution towards drainage. This phenomenon has been adequately predicted by the model.

\subsection{Atmosphere-soil-vegetation impacts on water balance}

The results of sensitivity analysis of soil moisture storage capacity $W_{\max }$, are presented in terms of mean and inter-annual variability of water fluxes. Figures 6 and 7 show the sensitivity of mean annual evapotranspiration and drainage to a range of soil moisture storage capacity values. As expected, the increase in $W_{\max }$ produces a beneficial increase in actual evapotranspiration and a corresponding decrease of drainage in Acacia and degraded forest cover when the soil moisture storage exceeds

Table 4. Simulated water balance component for selected land covers.

\begin{tabular}{llccrc}
\hline Year & Land cover type & $\begin{array}{c}\text { Rainfall } \\
(\mathrm{mm})\end{array}$ & $\begin{array}{c}\text { Discharge } \\
(\mathrm{mm})\end{array}$ & $\begin{array}{c}\text { Actual evaporation } \\
(\mathrm{mm})\end{array}$ & $\begin{array}{c}\text { Drainage/recharge } \\
(\mathrm{mm})\end{array}$ \\
\hline \multirow{2}{*}{2004} & Natural forest & 2846.31 & 894.9 & 865.31 & 1086.1 \\
& Degraded forest & & 1084.14 & 1499.44 & 214.69 \\
& Acacia & 868.94 & 802.98 & 1174.38 \\
2005 & Natural forest & 3632.70 & 1369.78 & 1163.33 & 1099.59 \\
& Degraded forest & & 1778.92 & 1490.46 & 176.72 \\
& Acacia & & 1605.83 & 990.63 & 1036.23 \\
\multirow{2}{*}{2006} & Natural forest & \multirow{2}{*}{3352.00} & 1255.11 & 1188.76 & 908.13 \\
& Degraded forest & & 1510.81 & 1495.69 & 237.15 \\
& Acacia & & 1250.02 & 677.48 & 1424.50 \\
& Natural forest & 4023.00 & 1508.86 & 1228.26 & 275.88 \\
& Degraded forest & & 2024.00 & 1517.48 & 1300.38 \\
\hline
\end{tabular}




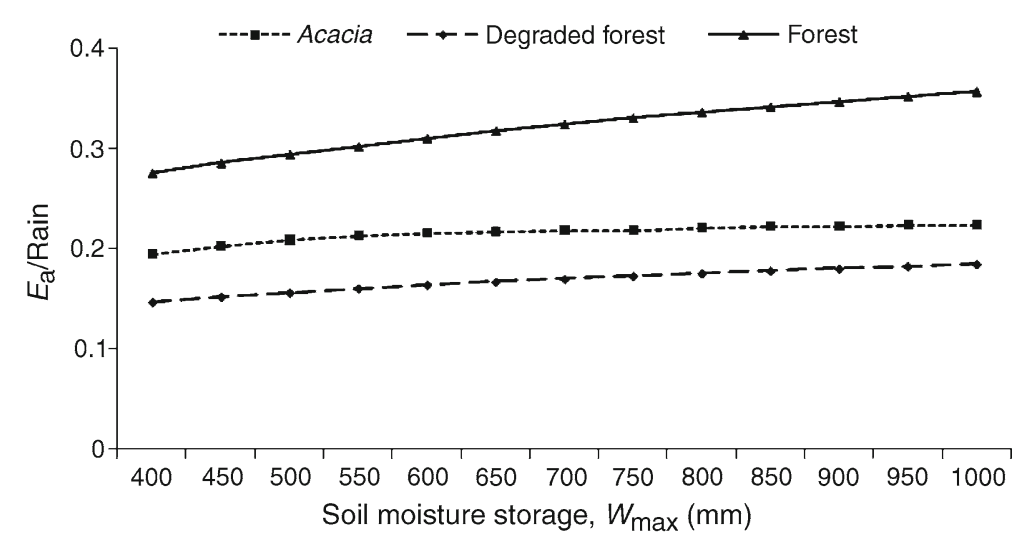

Figure 6. Sensitivity of the mean annual evapotranspiration to changes in soil moisture storage capacity $W_{\text {max }}$. These curves refer to mean annual values scaled by mean annual rainfall. $E_{\mathrm{a}}$ is based on the simulations of 4 years data.

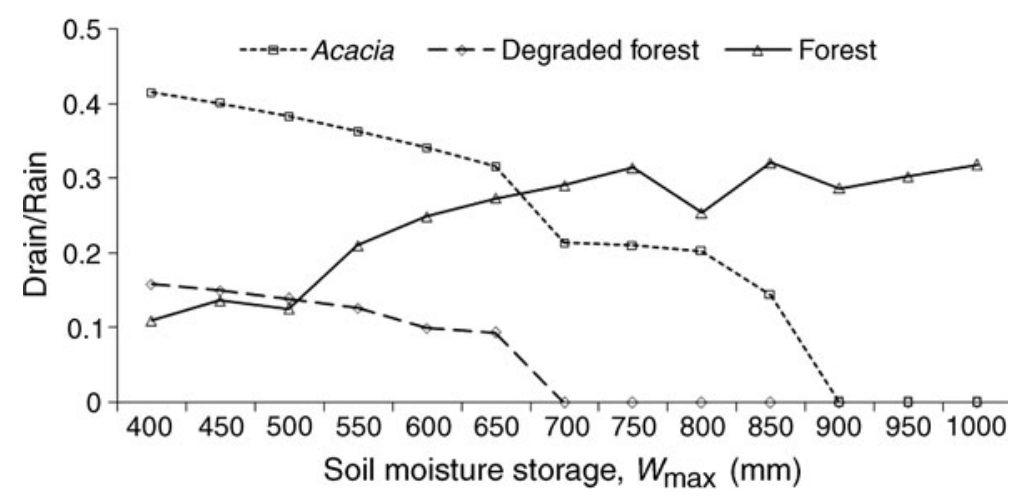

Figure 7. Sensitivity of the mean drainage values to changes in soil moisture storage capacity $W_{\text {max }}$. These curves refer to mean annual values scaled by mean annual rainfall. $E_{\mathrm{a}}$ is based on the simulations of 4-years data.

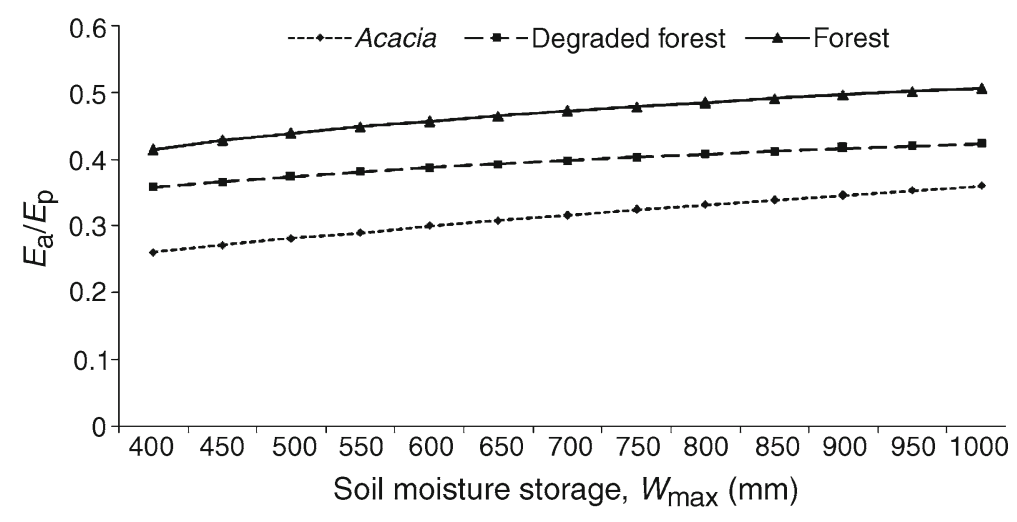

Figure 8. Influence of soil moisture storage on the ratio of actual to potential evapotranspiration under different land covers.

$700 \mathrm{~mm}$. However, under natural forest, it is observed that, there is an increase in evapotranspiration with increase in $W_{\max }$, and a simultaneous increase in the drainage component. Further, no incremental increase in the drain/rain ratio beyond $700 \mathrm{~mm}$ under degraded forest and $900 \mathrm{~mm}$ under Acacia was observed. This could be either due to higher contribution of rainfall towards the overland flow once the soil moisture exceeds field capacity of the soils under these land covers or the excess soil moisture content may be carried over to the next season. This sensitivity of the hydrological response to $W_{\text {max }}$ may be taken as an indication of the heterogeneity of actual evapotranspiration and drainage 
estimates across the study area, arising from the heterogeneity of soil storage properties and wateruse pattern of the tree species occupying the watershed. As can be seen from figures 6 and 7, water use of Acacia is not as high as natural forest, but slightly higher than the degraded forested watershed. This gives an indication that these plants are not mining soil moisture. This observation is in line with the results reported by the Kallarackal and Somen (2008).

Another important hydrological descriptor is the mean annual value of the actual evapotranspiration $E_{\mathrm{a}}$ scaled by the potential evapotranspiration $E_{\mathrm{p}}$ for selected land covers. The ratio represents the variable degree of adaptation in response to the water storage capacity of the soil. Figure 8 shows that Acacia has adapted itself to the climate of the region as well as the native forest.

\section{Summary and conclusions}

The nature of the land cover existing at the surface has significant influence on the hydrological regime. The temporal variability of soil moisture is considerably influenced by land cover and can have important ramifications on runoff generation. The Western Ghats region in South India is undergoing large-scale changes in land cover on account of deforestation and afforestation. Since this region forms the headwater for most of the peninsular rivers, understanding and predicting the effects of land cover changes on soil moisture are of paramount importance. With this objective, this study examines the suitability of a simple hydrological model for water balance evaluation and prediction of soil moisture values under conditions of limited data availability. A simple parametric model proposed by Georgakakos and Baumer (1996) was used to simulate soil moisture in the top $150 \mathrm{~cm}$ soil layer of watersheds located in Western Ghats and possessing three different land covers natural forest, degraded forest and Acacia plantation. The model was calibrated and validated with weekly soil moisture measurements made in the three watersheds over a 4-year period (2004-2008). Model performance both in calibration and validation was deemed reasonable for all three land covers as indicated by several performance statistics. Even though the structure of the model was simple and possessed only four parameters, the temporal pattern of soil moisture build-up and recession were reasonably well simulated. Interestingly, the optimal values of the four model parameters were significantly different for the three land covers indicating the ability of the model to capture the influence of land cover on soil moisture variations.

\section{References}

Allen R, Pereira L S, Raes D and Smith M 1998 Crop evapotranspiration. Guidelines for computing crop water requirements; Irrigation Drainage Paper No.56, FAO, Rome, Italy, 300p.

Atkinson S E, Woods R A and Sivapalan M 2002 Climate and landscape controls on model complexity; Water Resour. Res. 38(12) 1314-1330.

Aubert D, Loumagne C and Oudin L 2003 Sequential assimilation of soil moisture and stream flow data in a conceptual rainfall-runoff model; J. Hydrol. 280 145-161.

Beven K, Lamb R, Quinn P, Romanowicz R and Freer J 1995 TOPMODEL, In: Computer Models of Watershed Hydrology (ed.) Singh V P; Water Resources Publications, Highlands, Ranch, Co., pp. 627-668.

Blyth M 2002 Modelling soil moisture for a grassland and a woodland site in south-east England; Hydrol. Earth Syst. Sci. 6(1) 39-47.

Bonell M, Purandara B K, Venkatesh B, Krishnaswamy J, Acharya H A K, Singh U V, Jayakumar R and Chappell N 2010 The impact of forest use and reforestation on soil hydraulic conductivity in the Western Ghats of India: Implications for surface and sub-surface hydrology; J. Hydrol. 391(1-2) 47-62, doi: 10.1016/j. jhydrol.2010.07.004.

Bourgeon G 1989 Explanatory Booklet on the Reconnaissance of Soil Map of Forest Area: Western Karnataka and Goa (Pondicherry: Institut Francais de Pondichery).

Brocca L, Melone F and Moramarco T 2008 On the estimation of antecedent wetness conditions in rainfall-runoff modeling; Hydrol. Proc. 22(5) 629-642.

Bruijnzeel L A 1990 Hydrology of moist tropical forest and effects of conversion: A state of knowledge review; UNESCO, Paris and Vrije Universiteit, Amsterdam, The Netherlands, 226p.

Bruijnzeel L A 2004 Hydrological functions of tropical forest: Not seeing the soil for the trees?; Agric. Ecosyst. Environ. 104 185-228, doi: 10.1016/j.agee.2004.01.015.

Calder I R, Hall R L and Adlard P G 1992 Growth and Water Use of Forest Plantations (Chichester: John Wiley \& Sons), 381p.

Canadell J, Jackson R B, Ehleringer J R, Mooney H A, Sala O E and Schulze E D 1996 Maximum rooting depth of vegetation types at the global scale; Oceologia 108 583-595.

Federer C A 1979 A soil-plant-atmosphere model for transpiration and availability of soil water; Water Resour. Res. 15 555-562.

Federer C A 2002 BROOK90 A simulation model for evaporation, soil water and stream flow; documentation for version 4 and 3.2/3/4; Compass Brook, Durham, New Hampshire.

Federer C A, Vorosmarty C and Fekete B 2003 Sensitivity of annual evaporation to soil and root properties in two models of contrasting complexity; J. Hydrometeorol. 4 1276-1290.

Georgakakos K P and Baumer O W 1996 Measurement and utilization of on-site soil moisture data; J. Hydrol. 184 $131-152$.

Jha C S, Dutt C B S and Bawa K S 2000 Deforestation and land use changes in Western Ghats, India; Curr. Sci. 79(2) 231-238.

Kallarackal J and Somen C K 2008 Water loss from tree plantations in the tropics; Curr. Sci. 94(2) 201-210.

Kamath S U (ed.) 1985 Karnataka State Gazetteer: Uttara Kannada District, Gazetteer of India, Government of Karnataka, Bangalore. 
Lacambra L C J, Andray A B and Frances S F 2010 Influence of the soil water holding capacity on the potential distribution of forest species. A case study: The potential distribution of cork oak (Quercus suber L.) in central-western Spain; European J. Forest Resour. 129 111-117.

Legates D R and McCabe Jr G J 1999 Evaluating the use of 'goodness-of-fit' measures in hydrologic and hydroclimatic model validation; Water Resour. Res. 35 233241.

Maidment D R 1993 Handbook of Hydrology (New York: McGraw-Hill).

Milly P C D 1994 Climate, soil water storage, and average annual water balance; Water Resour. Res. 30(6) 21432156.

Nandagiri L and Kovoor G 2006 Performance evaluation of reference evapotranspiration equations across a range of Indian climates; J. Irrigation Drainage (ASCE) 132(3) $238-249$.

Scanlon T and Albertson J D 2003 Inferred control on tree/grass composition in a savanna ecosystem: Combining 16-year normalized difference vegetation index data with a dynamic soil moisture model; Water Resour. Res. 39(8) 1224-1237.

Scott D F, Bruijnzeel L A and Mackensen J 2004 The hydrological impacts of reforestation of grasslands, natural and degraded and of degraded forest in the tropics; In: Forests, Water and People in the Humid Tropics: Past, Present and Future Hydrological Research for Integrated Land and Water Management (eds) Bonell $\mathrm{M}$ and Bruijnzeel L A; UNESCO International Hydrology Series (Cambridge: Cambridge University Press), pp. 622-651.

Struthers I, Hinz C, Sivapalan M, Deutschman G, Beese F and Meissner R 2003 Modelling the water balance of a free-draining lysimeter using the downward approach; Hydrol. Proc. 17 2151-2169.

Thornthwaite C W and Mather J R 1957 Instructions and tables for computing potential evapotranspiration and the water balance; Publication in Climatology 10(3) (New Jersey: C.W. Thornthwaite \& Associates).

USDA 2008 Natural Resources Conservation Services; National Soil Survey Hand Book, 430 p.

Vandana S and Bandyopadhyay 1983 Eucalyptus - a disastrous tree for India; Ecologist 13 184-187.

Wilson D J, Western A W and Grayson R B 2005 A terrain and data based method for generating the spatial distribution of soil moisture; Adv. Water Resour. 28 $43-54$.

Zobel R W 1992 Soil environmental constraints to root growth; Adv. Soil Sci. 19 27-51. 